\title{
EUROCENTRISMO E A PANDEMIA DE COVID-19 NO CONTINENTE AFRICANO: AFINAL, O QUE SABEMOS?
}

\author{
EUROCENTRISM AND THE COVID-19 PANDEMIC IN THE AFRICAN \\ CONTINENT: AFTER ALL, WHAT DO WE KNOW?
}

\section{EUROCENTRISME ET PANDÉMIE COVID-19 DANS LE CONTINENT AFRICAIN: APRÈS TOUT, QUE SAVONS-NOUS?}

Rafael Alves de Freitas ${ }^{1}$

\section{Resumo}

A pesquisa aqui desenvolvida buscou, mas sem a pretensão de esgotar o assunto, refletir brevemente sobre como a mídia hegemônica brasileira nos informou sobre a pandemia de Covid-19 no continente africano. Essa investigação se deu nos meses de março e abril de 2020, onde buscou-se por matérias dos principais sites responsáveis pela formação de opinião no leitor e por isso escolhidas para tal. Dessa forma, partindo de uma análise crítica dos textos noticiados, esboçamos um paralelo entre o Eurocentrismo com a pandemia na África e de que forma esses textos refletiram uma visão eurocêntrica, reforçando estereótipos e normalizando o continente como palco de excelência para desastres.

Palavras-chave: Continente africano. Covid-19. Eurocentrismo. Mídia. Informação.

\section{Abstract}

The research developed here sought, but without the intention of exhausting the subject, to reflect briefly on how the Brazilian hegemonic media informed us about the Covid-19 pandemic in the African continent. This investigation took place in the months of March and April 2020, in which we searched for articles from the main opinion makers websites, and therefore chosen for this. Thus, starting from a critical analysis of those articles, we have drawn a parallel between Eurocentrism and the pandemic in Africa and how these texts reflected the Eurocentric vision, reinforcing stereotypes and keeping the continent as a disaster masterpiece. Keywords: African continent. Covid-19. Eurocentrism. Media. Information.

\section{Résumé}

La recherche développée ici a cherché, mais sans intention d'épuiser le sujet, à réfléchir brièvement sur la façon dont les médias hégémoniques brésiliens nous ont informés de la pandémie de Covid-19 sur le continent africain. Cette enquête a eu lieu dans les mois de mars et avril 2020, où nous avons recherché des articles sur les principaux sites d'information, chargés de se forger une opinion avec ses lecteurs et donc choisis pour cela. Ainsi, à partir d'une analyse critique de ces articles, nous avons établi un parallèle entre l'eurocentrisme et la pandémie en Afrique et comment ces textes reflétaient la vision eurocentrique, renforçant les stéréotypes et faisant du continent un chef-d'œuvre de catastrophe.

Mots-clés: Continent africain. Covid-19. Eurocentrisme. Médias. Information.

\footnotetext{
${ }^{1}$ Mestrando em Geografia pela Universidade Federal Rural do Rio de Janeiro (PPGGEO-UFRRJ). Possui Licenciatura Plena em Geografia pela Universidade do Estado do Rio de Janeiro (UERJ), além de ser Bacharel em Sistemas de Informação pela Fundação Educacional Unificada Campograndense (FEUC). Membro/Pesquisador do Grupo de Estudos Integrados em Ambiente: Geografia e Ensino (GEIA) - Universidade Federal Rural do Rio de Janeiro (UFRRJ). E-mail: uerj.raf@gmail.com
} 
Eurocentrismo e a pandemia de Covid-19 o continente africano: afinal, o que sabemos?

\section{INTRODUÇÃO}

O escravo moderno não difere do senhor apenas pela liberdade. Mas ainda pela origem. Pode-se tornar livre o negro, mas não seria possível fazer com que não ficasse em posição de estrangeiro perante o europeu. E isso ainda não é tudo: naquele homem que nasceu na degradação, naquele estrangeiro introduzido entre nós pela servidão, apenas reconhecemos os traços gerais da condição humana. O seu rosto parece-nos horrível, a sua inteligência parece-nos limitada, os seus gostos são vis, pouco nos falta para que o tomemos por um ser intermediário entre o animal e o

Este trabalho é fruto de reflexões acerca da pouca informação (por vezes nenhuma) que temos aqui no Brasil sobre a pandemia de Covid-19 no continente africano. Nkali é uma palavra da etnia nigeriana lgbo que carrega como significado -"ser maior que o outro". Essa palavra é usada para explicar como as relações de poder influenciam as histórias, ou seja, como são escritas, quem as conta, quando e quantas são publicadas. E o pior, muitas vezes contada apenas por quem vence.

Chimamanda Ngozi Adichie popularizou esse termo em sua palestra - "O perigo de uma única história”, no TED Talks (ADICHIE, 2013). Por cerca de dezenove minutos, a escritora nigeriana discorre sobre como a visão ocidental ajudou a criar no imaginário comum social a imagem de uma África subserviente e caracterizada por mazelas das mais diversas. Hoje, sete anos depois da palestra de Chimamanda, em meio à pandemia do coronavírus que paralisou o mundo, a grande mídia hegemônica brasileira mostra como funciona, na prática, a influência do Eurocentrismo. Logo, Nkali está exemplificada nas histórias que as mídias nacionais escolheram contar ou não contar sobre a disseminação da Covid-19 no continente africano.

Nessa direção, o objetivo aqui é refletir por meio da crítica sobre como a mídia brasileira tem informado ou não sobre a pandemia na África. O que chega até nós? Como chega? Assim, para se alcançar esse objetivo, usou-se uma metodologia qualitativa de pesquisa, considerando alguns sites de notícias (G1, Folha de São Paulo e $U O L$ ) que por serem hegemônicos são responsáveis pela maioria das informações que chegam ao leitor. Assim, a referida pesquisa se deu entre os meses de março e abril de 2020, onde buscou-se por meio desses sites notícias veiculadas em relação à pandemia de Covid-19 na África.

\section{EUROCENTRISMO: BREVES PONDERAÇÕES}

Para entender a visão que temos de África é preciso remontar ao período do Imperialismo, também chamado por alguns autores como Neocolonialismo, e que foi impulsionado pelo advento da Segunda Revolução Industrial. Com isso, o objetivo era explorar "áreas desconhecidas" - (o continente africano foi o melhor exemplo) em busca de matérias primas que alimentassem as indústrias das áreas colonizadoras (países europeus), reforçando assim o processo de dominação e conquista tanto política quanto econômica dos colonizados (BARBOSA, 2008). Essa situação é reforçada no quadrinho da Figura 01 - (As aventuras de 
Eurocentrismo e a pandemia de Covid-19 o continente africano: afinal, o que sabemos? Tintim, produzidos na década de 1930), pois encontramos características utilizadas para justificar a missão civilizatória europeia por meio da superioridade do homem branco.

Figura 01: Tintim, um jornalista belga em uma visita ao Congo em 1930.

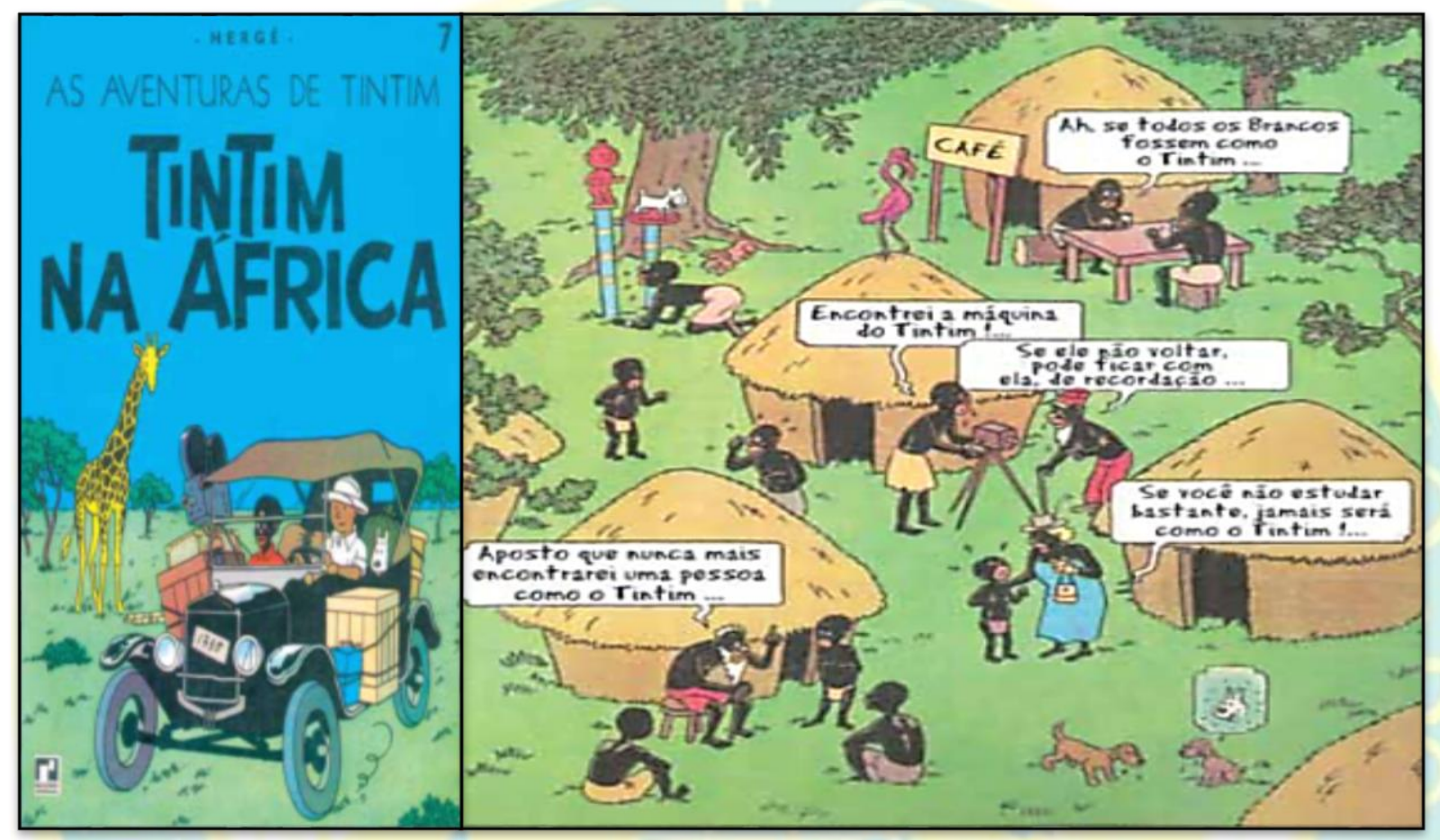

Fonte: HERGÉ, 1975.

Tintim é um jovem repórter belga e faz uma expedição ao Congo, colônia do seu país à época, e é visto como homem inteligente, desenvolvido e bondoso, como se percebe pelos diálogos da figura. Essa leitura ratifica a noção de superioridade do europeu sobre o africano, e serviu como base utilizada na justificativa europeia para a Conferência de Berlim na segunda metade do século XIX, mais precisamente em 1884. Essa conferência serviu para propagar ideias de que os indígenas americanos, africanos e asiáticos seriam selvagens e que por isso não poderiam se autogovernar, "justificando" assim as explorações. Dessa forma, a África teve porções do seu território fragmentadas/partilhadas, sendo invadidas/colonizadas por nações europeias, não levando em conta as fronteiras culturais já existentes, o que nos ajuda a entender também os diversos conflitos separatistas, inclusive armados, existentes até hoje no continente (BARBOSA, 2008).

Por isso, na historiografia, a Europa ocupou e ocupa o espaço de referência, daí o termo Eurocentrismo, e serviu como modelo de desenvolvimento para o mundo. Em sua colonização, a Europa impôs a sua identidade e neutralizou qualquer vestígio de cultura que não fosse a sua própria. Assim, o Eurocentrismo foi responsável por desvalorizar identidades locais (QUIJANO, 2005). Consequentemente, nos dias de hoje, em meio à pandemia, vemos que a mídia brasileira limita-se a reproduzir as informações 
Eurocentrismo e a pandemia de Covid-19 o continente africano: afinal, o que sabemos?

prontas e acabadas das agências internacionais (europeias e estadunidenses), o que já mostra um certo equívoco.

Assim, vemos o Eurocentrismo ainda presente nos nossos dias, quer sejam pelas músicas que ouvimos, quer sejam pelos filmes e seriados que assistimos e, reflete nos nossos interesses à medida que consumimos essas produções. Logo, somos influenciados por essa massa de produtos provenientes da globalização perversa que nos cerca. E a mídia de comunicação e informação é uma extensão disso.

Nesse contexto, um paradoxo se observa. Porque fomos condicionados, incluindo o Brasil, de assimilar a retórica de enxergar em outros povos - (os africanos de modo geral) a negatividade e principalmente a inferioridade. Porém, o Brasil, enquanto um país que também foi colonizado, nesse caso pelos portugueses - tendo um povo tão miscigenado e com forte ligação cultural com o africano e com a própria África -, como pode endossar essa imagem preoconceituosa. E aqui fica a reflexão. Essa retórica pode ser explicada em grande parte pela influência do Eurocentrismo e do estilo norte-americano, e somos assim levados por essa lógica globalizante que permeia o nosso imaginário e que tanto nos limita.

Portanto, essa imagem negacionista, muitas vezes não leva em consideração o fato do continente africano ser heterogêneo, nos levando a uma "alienação" e até mesmo na confusão que infelizmente muitos fazem quanto a diferença entre o continente africano do país África do Sul (QUIJANO, 2005). E aqui vale uma crítica, pois essa visão é colaborada muitas vezes pelos próprios livros didáticos, que colocam o preto sempre como escravo e numa posição inferior, o que vai ao encontro daquilo que se entende como "verdade absoluta" por meio dos processos de exploração e que são tão intranhados no imaginário comum, se fazendo refletir pela mídia em geral.

\section{O PERIGO DA HISTÓRIA ÚNICA E CONTADA POR QUEM VENCE}

Quando Edward Said (palestino) escreve na década de 1970 o livro "Orientalismo", ele estava buscando trazer para o debate acadêmico ocidental as visões estereotipadas e preconceituosas que eram atribuídas a tudo que fosse "diferente", que fosse "distante", que fosse "oriental". Ele fala - "O Oriente era quase uma invenção europeia e, fora desde a Antiguidade um lugar de romance, de seres exóticos, de memórias e paisagens obsessivas, de experiências notáveis" (SAID, 1990. p. 13). No decorrer dos seus estudos ele vai demostrando que tudo que não era europeu - e posteriormente norte-americano - era considerado estranho, patológico, clandestino, violento, infantil, obsoleto ou precário, e isso se aplica também e, principalmente, à África. Era sempre um lugar, uma cultura que era vista por pessoas "de fora" e julgada segundo valores também exóticos. Essas visões europeias ou norte-americanas eram entendidas como "verdades absolutas", pois eram asseguradas pela "autoridade" do saber (SAID, 1990).

Esse autor anuncia um novo tempo em que se notou que não era mais possível o mundo inteiro ser entendido e avaliado segundo a lógica, a cultura e os valores de um único e pequeno grupo: os brancos europeus. Por mais que esses tenham dominado grande parte do planeta politicamente, culturalmente e também de forma militar, a maneira de ser e pensar do europeu branco não é a única maneira de pensar da 
Eurocentrismo e a pandemia de Covid-19 o continente africano: afinal, o que sabemos? humanidade (SAID, 1990). Devemos então perguntar sobre a validade desta "autoridade" que nega a autonomia de outros grupos e outras vozes. Ele deu início ao que hoje chamamos de estudos pós-coloniais. Outros autores também tiveram a coragem de se colocar como sujeitos dos seus pensamentos e romper com os estereótipos que lhes eram impostos por serem latino-americanos, indígenas, negros, mulheres ou de outro grupo não hegemônico.

Nesse sentido, ainda em direção ao pensamento do autor (1990), quando se fala de África é sempre com distanciamento, com repulsa, com medo. É como se o continente fosse palco de excelência para desastres dos mais diversos. Afinal, falar dos países da África, sem conhecer a realidade dos mesmos, é apenas reforçar mitos que em nada contribuem com a diversificação que encontramos no continente.

Por tudo isso, ao observarmos as notícias veiculadas no Brasil, por meio de alguns sites sobre a pandemia de Covid-19 na África, constatamos certa invisibilidade da mídia para esse continente, que aliás, é o terceiro maior do mundo, que reúne o maior número de países - 54, e ocupa o segundo lugar no ranking populacional, de jovens inclusive. Assim, na busca por informações, por exemplo, sobre o número de óbitos na África, como o continente tem encarado a pandemia, quais têm sido as ações políticas, quais suas consequências imediatas para a população e etc, percebemos a persistência, ora alternada pela ausência de informação, ora alternada por uma visão eurocêntrica nos textos noticiados. A título de elucidação, trazemos o Mapa 01, que mostra o continente africano, seus países e respectivos colonizadores europeus.

Mapa 01: Divisão política da África e seus colonizadores.

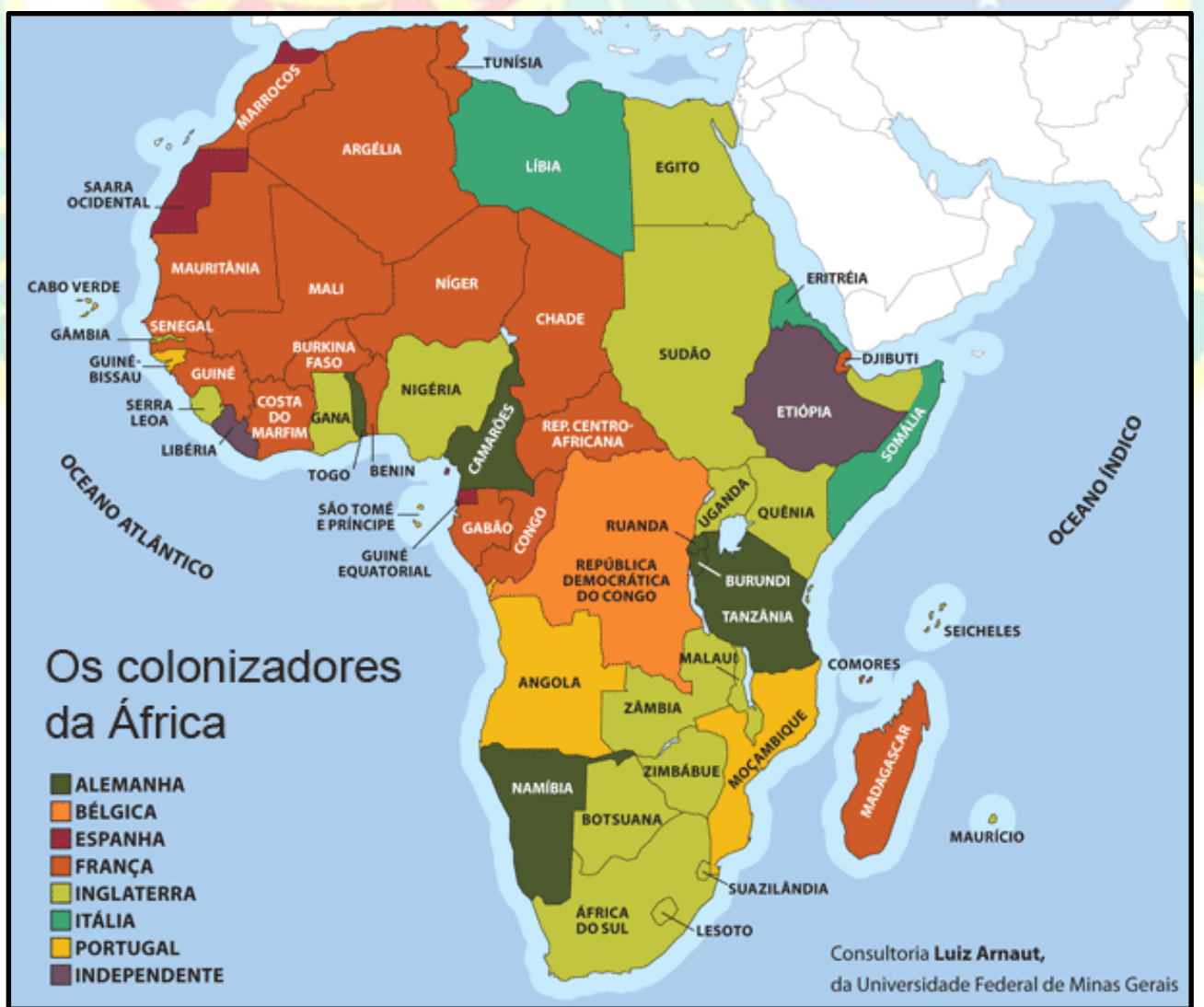

Fonte: Luiz Arnaut - Universidade Federal de Minas Gerais (2008). 
Não é de hoje que a África recebe um olhar homogêneo, superficial e preconceituoso do mundo. Repleta de estereótipos, a visão é muito polarizada - ou se restringe às questões de miséria e desgraça, ou à narrativa fantasiosa de riquezas naturais abundantes construídas pela ambição europeia, quando não limitada às savanas, dando ideia de uma África povoada apenas por animais de grande porte, servindo para a prática de safari, e nada mais.

É importante dizer que o vocábulo - estereótipo, grosso modo, significa uma visão errônea que temos de algo ou de alguém, mas que por força da repetição se torna "verdadeiro" pelo senso comum, muito em virtude da falta de conhecimento, e claro da própria mídia, que nesse contexto, nunca se esforça para mostrar uma outra África, persistindo numa singularidade que não existe, desconsiderando assim a geografia do continente. Como disse a escritora Chimamanda Adichie (2013) - "se ouvimos somente uma única história sobre outra pessoa ou país, corremos o risco de gerar grandes mal-entendidos".

\section{PANORAMA DA MÍDIA HEGEMÔNICA SOBRE A PANDEMIA NO CONTINENTE AFRICANO}

Um dos principais sites de notícias do Brasil, "O Globo", optou por uma abordagem numérica, e nada humanizada, depois de informar o primeiro caso de Covid-19 na África, mas especificamente no Egito, no dia 14 de fevereiro. Embora haja contradição nessa informação, visto que por conta da ditadura de alguns países africanos, não se sabe ao certo a situação real da pandemia nesses países, o que compromete inclusive a divulgação de dados oficiais.

O jornal O Globo realizou coberturas massivas sobre os países da Europa, sobre a China e até mesmo sobre estados estadunidenses, mas o padrão não se repetiu com as regiões africanas. Na maioria das atualizações dos dados nos meses de março e abril, os números foram replicados de agências internacionais europeias, e não houve menção a fontes locais.

O Mapa 02 traz de forma qualitativa os números de casos confirmados por países africanos - (quanto mais forte for a cor, mais casos foram confirmados no referido país), e o próprio título diz que o número real é ainda maior, mas em virtude da falta de testes, esses números acabam sendo defasados. 
Mapa 02: Total de casos confirmados de COVID-19 na África até o dia 30 de abril. O número de casos confirmados é menor que o número real em virtude de testes limitados para o diagnóstico da doença.

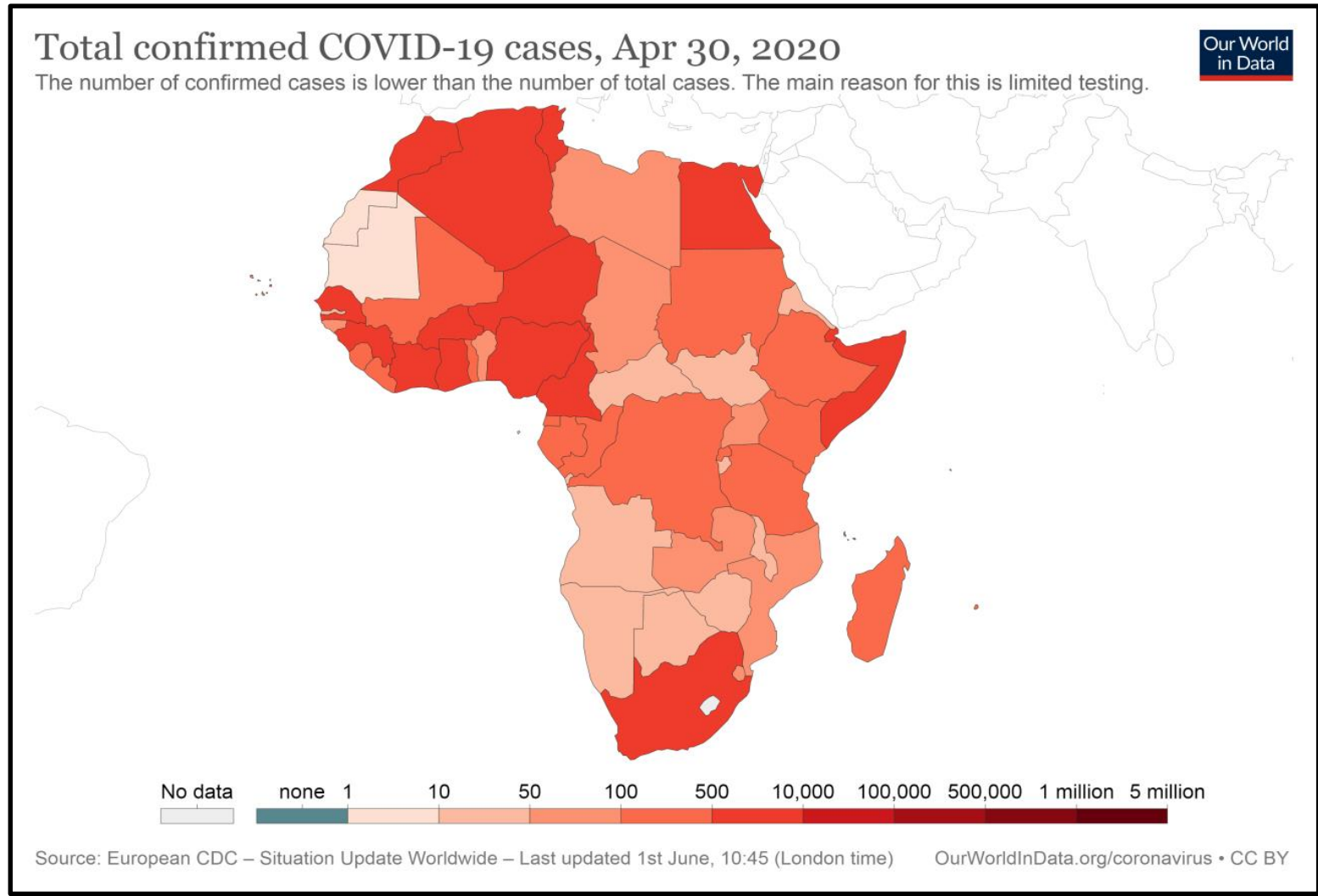

Fonte: Coronavírus na África: siga, com mapas e gráficos, a situação da pandemia no continente. Disponível em: <https://operamundi.uol.com.br/coronavirus/64231/coronavirus-na-africa-siga-com-mapas-e-graficos-asituacao-da-pandemia-no-continente>.

Acessado em 30 de abril de 2020.

Enquanto o vírus avançava nos países do continente africano, o site brasileiro fechava os olhos. Praticamente durante o mês de março inteiro, o jonal - oglobo.com, não mencionou detalhes sobre qualquer um dos 54 países africanos. A única exceção foi no dia 09 de março, em um texto publicado em parceria com o site G1. A matéria destacava as doações que a Fundação Bill Gates realizou para fundos emergenciais da China e da África. Segundo os portais, o auxílio financeiro seria destinado a medidas técnicas, de proteção e diagnóstico porque não havia casos da doença no continente africano. Mas, naquele 09 de março, o vírus já tinha acometido dezenas de pessoas, segundo dados de alguns jornais africanos, como o jornal Egypt Independent. O erro comum aos veículos hegemônicos do país demonstra uma atitude mista de ingenuidade com negligência por parte da mídia. Contudo, acreditamos na segunda hipótese.

Em uma análise quantitativa da cobertura por parte do portal de notícias G1 durante os meses de março e abril, o que mais se destacou foi o olhar do G1 permeado por uma indiferença ao continente africano. Percebemos que a maioria das matérias com referência à África apresentava apenas uma contagem dos casos por país, sem aprofundamento, sem humanidade, tratando apenas como números isolados. Em 
Eurocentrismo e a pandemia de Covid-19 o continente africano: afinal, o que sabemos? grande parte, resumos diários onde a China - o epicentro da pandemia - e o continente europeu recebiam destaque, e diga-se de passagem, de forma massificante.

Assim, o G1 reproduziu matérias compradas de agências internacionais, que inevitavelmente foram marcadas pelo olhar eurocêntrico, embora com pouquíssimas matérias que de fato refletiam a realidade do continente africano, cuja fonte era a União Africana.

Nessa análise, percebemos muitas matérias jornalísticas onde se acentuavam o olhar do colonizador sobre a África. É o caso da matéria reproduzida da Reuters (2020) -“Escassez de produtos frescos deve afetar Europa em meio a paralisações por coronavírus". O texto alertava sobre o fechamento das fronteiras entre os continentes africano e europeu, e discorre sobre o possível impacto da Europa pelo desabastecimento de produtos alimentícios vindos da África. Embora conte com o pronunciamento de Okisegere Ojepat, presidente-executivo do Consórcio de Produtos Frescos do Quênia, o enfoque da matéria era muito mais sobre o futuro da Europa, suas consequências em vitude da pandemia de Covid-19 ao invés de uma leitura sobre a economia dos países exportadores e seus trabalhadores. Afinal, é como se a África fosse por excelência palco de desgraças, gerando uma certa normalização dos seus problemas, que são históricos, aliás.

Contudo, vimos também abordagens midiáticas, como da $U O L$, oferecendo uma opção de leitura com temas mais humanizados sobre o continente. De assuntos como a situação caótica em um determinado país africano até a relação existente no avanço do autoritarismo com a pandemia, o portal de notícias se destacou por seus recortes específicos sobre a África.

A partir de um tom mais humano e com viés crítico, talvez tentando aproximar e/ou sensibilizar o leitor para uma realidade nem tão distante, muitas publicações utilizaram falas dos próprios moradores locais. A matéria do portal UOL, do dia 02 de abril - replicada da AFP - Agence France-Presse, KHAYELITSHA (2020), por exemplo, expôs a realidade de uma sul-africana vivendo em um ambiente inóspito, estilo cortiço, com apenas um cômodo e sem janela. O leitor desse texto era levado a questionar como a mulher nele retratada pode compreender o isolamento social. É injusto e hipócrita cobrar que a mesma regra seja aplicada a ela, tal como denuncia a própria reportagem, ao considerar um isolamento "totalmente ilusório", desconsiderando a realidade local da África do Sul.

A matéria - "Pandemia atinge África de maneira desigual e reflete constraste entre países" (ALENCASTRO, 2020), por exemplo, traça um paralelo entre África do Sul, Angola e Moçambique. A matéria proporciona ao leitor uma compreensão das diferentes realidades nos três países. O texto comenta os impactos do fechamento de fronteiras da África do Sul na economia de Moçambique. Porém, a crítica que fica é: Quantas vezes já não lemos em outros veículos sobre os impactos econômicos que medidas estadunidenses causam nos países emergentes e periféricos? Nem mesmo tomamos ciência das importantes ligações econômicas que países emergentes e periféricos, como os africanos, possuem entre si. Essa matéria então nos leva a pensar que, vários problemas dos países africanos mencionados pelo $U O L$ já existiam antes da pandemia. 


\section{Eurocentrismo e a pandemia de Covid-19 o continente africano: afinal, o que sabemos?}

Entre os demais veículos da mídia hegemônica, cabe destacar também o site da Folha de São Paulo. Ao se propor apresentar matérias mais focadas em dados científicos e falas de autoridades no assunto, a Folha de São Paulo recorreu principalmente a especialistas e pesquisadores africanos, assim como pelos pronunciamentos da Organização Mundial da Saúde - OMS e de líderes de Estado do continente como fontes para as notícias veiculadas.

$\mathrm{Na}$ coluna "Jornalista angolano escreve sobre custo político e social da Covid-19 no país" (AZEVEDO, 2020), o site da Folha de São Paulo reconhece que o espaço da mídia é essencial para uma ampla construção do imaginário do leitor. Essa matéria traz uma profunda análise do contexto político e econômico em que a Angola estava antes da Covid-19 e como a pandemia tem dificultado a implementação de políticas de combate e prevenção à doença no país, sem falar de doenças como a AIDS, o Ebola e outras, tão bem conhecidas pelos africanos há tempos.

Entretanto, a Folha de São Paulo também apresentou uma visão eurocêntrica em algumas de suas coberturas. Mesmo com o primeiro caso no continente africano tendo sido registrado dia 14 de fevereiro, a primeira notícia específica sobre a África foi veiculada no site somente dia 01 de março. O destaque para a fala de Tedros Ghebreyesus, diretor-geral da Organização Mundial da Saúde - OMS, no título da matéria, indica que o motivo da não veiculação da notícia sobre a África até então, foi a crença de que era preciso que tal informação fosse dada por especialistas.

O texto de Marilza de Melo Foucher (2020), "O coronavírus retira a máscara da ideologia neoliberal", publicado no dia 17 de março, critica o fato de que o aspecto econômico se sobressaia às urgências humanitárias. A autora critica o despreparo e a demora de ações dos países mais ricos em conter a disseminação do vírus, em virtude de numa cautela em proteger o sistema econômico neoliberal. Curiosamente, esse texto foi escrito para um portal - Brasil 247, que em nada faz parte da cadeia hegemônica de informação jornalística do Brasil.

Em suma, constatamos que o Eurocentrismo ainda se reflete nos nossos dias, embora nem sempre de forma explícita, até porque com o passar do tempo o Eurocentrismo sofre atualização, a tal ponto de não percebermos mais de imediato, e que talvez seja o grande perigo. Esse perigo, para além de uma história contada pelo outro (nunca pelo próprio africano, por aquele que conhece e vive a realidade), ainda temos o perigo de normalizarmos os problemas do continente africano, atribuindo a ele quase que um valor místico. E nessa direção, a mídia hegemônica brasileira ratifica essa visão eurocêntrica até aqui exposta. Não é tão simples julgar intenções da mídia, mas o fato é que a grande maioria das reportagens que coletamos para esta pesquisa mostrou um olhar pouco profundo sobre a pandemia no continente.

\section{CONSIDERAÇÕES FINAIS}

O subtítulo desse trabalho propositalmente questiona ao leitor (que vale também para nós, autores), sobre o que sabemos da pandemia de Covid-19 no continente africano. Assim, esse momento do texto serve muito mais para sintetizarmos as reflexões até aqui expostas, do que necessariamente nos preocuparmos com 
Eurocentrismo e a pandemia de Covid-19 o continente africano: afinal, o que sabemos? respostas prontas para a discussão em tela. Apesar das poucas exceções, a mídia brasileira não foge da ideia Nkali, que comentamos no início do texto. O problema é muito maior do que simplesmente informar sobre a pandemia na África pelos meios de comunicação. A questão urgente está na própria visão do Eurocentrismo e que se reflete nos textos que são elaborados, afinal, são elaborados por quem e para quem? Logo, uma nova pergunta que emerge é: Como desconstruir uma ideia etnocêntrica tão forte e enraizada nos meios de comunicação? Assim, como retratar a história e o passado ricos da África em uma narrativa justa, em um local de poder? É difícil considerar todos esses aspectos quando, cada vez mais, nota-se a invisibilização dos países africanos para a mídia.

Percebemos então que não há uma história única sobre determinado lugar. Ao construir uma narrativa, incorporamos a nossa cultura e os nossos preconceitos. Insistimos em propagar um imaginário excludente - a visão de um grande país chamado “África”, lugar de miséria e desastres, à espera de ajuda. O ato de reconhecer que estamos impregnados, presos, imersos no Eurocentrismo já é um grande passo para compreender a necessidade de descolonizar a nós mesmos, antes da mídia fazê-la. Se é que fará!

\section{REFERÊNCIAS}

ADICHIE, Chimamanda. Vídeo do YouTube - O perigo de uma única história. TED Talks - 23 de fevereiro de 2013. Disponível em: <https://www.youtube.com/watch?v=wQk17RPuhW8>Acessado em 20 de março de 2020.

ALENCASTRO, Mathias. UOL - Pandemia atinge África de maneira desigual e reflete constraste entre países. Fonte: $\lfloor$ https://www1.folha.uol.com.br/mundo/2020/04/pandemia-atinge-africa-de-maneira-desiguale-reflete-contraste-entre-paises.shtml> Acessado em 12 de abril de 2020.

AZEVEDO, Dodô. Folha de São Paulo - Jornalista angolano escreve sobre custo político e social da Covid-19 no país. Fonte: <https://quadronegro.blogfolha.uol.com.br/2020/04/09/jornalista-angolanoescreve-sobre-custo-politico-e-social-da-covid-19-no-pais/> Acessado em 09 de abril de 2020.

BARbOSA, Muryatan Santana. Eurocentrismo, História e História da África. Sankofa. Revista de História da África e de estudos da Diáspora Africana No 1 jun./2008.

FOUCHER, Marilza de Melo. Brasil 247 - Coronavírus retira a máscara da ideologia neoliberal. Fonte: $<$ https://www.brasil247.com/blog/o-coronavirus-retira-a-mascara-da-ideologia-neoliberal > Acessado em 16 de março de 2020.

HERGÉ. Tintim na África. Rio de Janeiro: Record, 1975.

KHAYELITSHA, África do Sul, AFP - Agence France-Presse. (UOL) - Nos bairros marginais da África do Sul, um confinamento totalmente ilusório. Fonte: <https://noticias.uol.com.br/ultimasnoticias/afp/2020/04/02/nos-bairros-marginais-da-africa-do-sul-um-confinamento-totalmente-ilusorio.htm>

Acessado em 02 de abril de 2020.

QUIJANO, Anibal. Colonialidade do poder, eurocentrismo e América Latina. IN IN:LANDER, Edgardo. A colonialidade do saber: eurocentrismo e ciências sociais perspectivas latinoamericanas. Buenos AiresClascso, 2005. 
Eurocentrismo e a pandemia de Covid-19 o continente africano: afinal, o que sabemos?

REUTERS. O Globo (G1) - Escassez de produtos frescos deve afetar Europa em meio a paralisações por coronavírus. Fonte: <https://g1.globo.com/economia/agronegocios/noticia/2020/03/26/escassez-deprodutos-frescos-deve-afetar-europa-em-meio-a-paralisacoes-por-coronavirus.ghtml $>$ Acessado em 26 de março de 2020.

SAID, Edward W. Orientalismo: o Oriente como invenção do Ocidente / Edward W. Said; tradução Tomás Rosa Bueno. São Paulo: Companhia das Letras, 1990.

TOCQUEVILLE, Alexis. A democracia na América. Belo Horizonte, Editora Itatiaia / São Paulo, Editora da USP, 1977.

Texto recebido em: $14 / 06 / 2020$

Texto aprovado em: 18/04/2021 